\title{
Interactional Effect of the Influential Parameters on Seismic Behaviour of the Concrete Surface Tanks
}

\author{
Alirezar Hassanpour Yasaghi, ${ }^{1}$ Mazhar Fatahi ${ }^{(D)},{ }^{2}$ and Seyed Mehdi Seyed Alizadeh ${ }^{3}$ \\ ${ }^{1}$ Department of Civil Engineering, Islamic Azad University, Mashhad, Iran \\ ${ }^{2}$ Department of Civil Engineering, Loghman Hakim Golestan Non-Profit Institute, Agh-Ghala, Iran \\ ${ }^{3}$ Petroleum Engineering Department, Australian College of Kuwait, West Mishref, Kuwait, Kuwait \\ Correspondence should be addressed to Mazhar Fatahi; mazharfatahi@gmail.com
}

Received 7 November 2020; Revised 4 December 2020; Accepted 24 December 2020; Published 16 January 2021

Academic Editor: Seyed Mahdi Seyed Kolbadi

Copyright (c) 2021 Alirezar Hassanpour Yasaghi et al. This is an open access article distributed under the Creative Commons Attribution License, which permits unrestricted use, distribution, and reproduction in any medium, provided the original work is properly cited.

\begin{abstract}
Given to the importance of the tanks and their various applications in different industries, studying the seismic behaviour of these facilities is essential. In such structures, obtaining exact theoretical solution for the seismic behaviour of the tanks is very difficult due to the existence of the soil-structure interaction. In this study, seismic behaviour studying has been taken into account and in addition to considering three-dimensional model of finite element model of a surface rectangular tank and its beneath soil given to SSI and FSI effect, we have done required analysis and Drucker-Prager nonlinear model has been used to investigating more exactly to describe soil behaviour. Euler-Lagrange view with optional mesh displacement has been used for modelling tank-water interaction. According to the obtained results from this modelling, soil beneath the tank and soil-structure interaction affect highly on seismic behaviour of the surface tanks. Meanwhile, the response of the structure to the density changes and soil modulus of elasticity is more sensitive and changes in the coefficient of friction coefficient between the foundation surface and the soil and the internal friction angle do not have tangible effect on the response. The results reveal that the liquid containers response is more sensitive to the changes of the density and the soil modulus of elasticity more than friction coefficient between the surfaces and foundation and internal angle friction.
\end{abstract}

\section{Introduction}

Due to the expansion of cities and the development of industries, the need for storage tanks for fluids such as water, oil, chemicals, and fuel has increased. One of the main pressures on this kind of structures is the pressure of the earthquake and considering that the country is very seismic then maintenance and continuous exploitation of such facilities when earthquake is occurred and after that is essential. For example, water tanks hitting due to earthquake will lead to significant problems such as inability to extinguish fire results from earthquake and lack of access to potable water. Selected model, concrete surface tank to supply potable water, is obtained according to the actual tank which was established in 1395 in Kermanshah (Figure 1).
Given to the importance of the tanks and their various applications in different industries studying the seismic behaviour of these facilities is essential. In such structures, obtaining exact theoretical solution for the seismic behaviour of the tanks is very difficult due to the existence of the soil-structure interaction. In this study, seismic behaviour studying has been taken into account and in addition to considering three-dimensional model of the finite element model of a surface rectangular tank and its beneath soil given to SSI and FSI effect, we have done required analysis and Drucker-Prager nonlinear model has been used to investigating more exactly to describe soil behaviour. Euler-Lagrange view with optional mesh displacement has been used for modelling tank-water interaction.

Up to date, various studies have been conducted regarding seismic behaviour of the tanks. Jacobsený was 

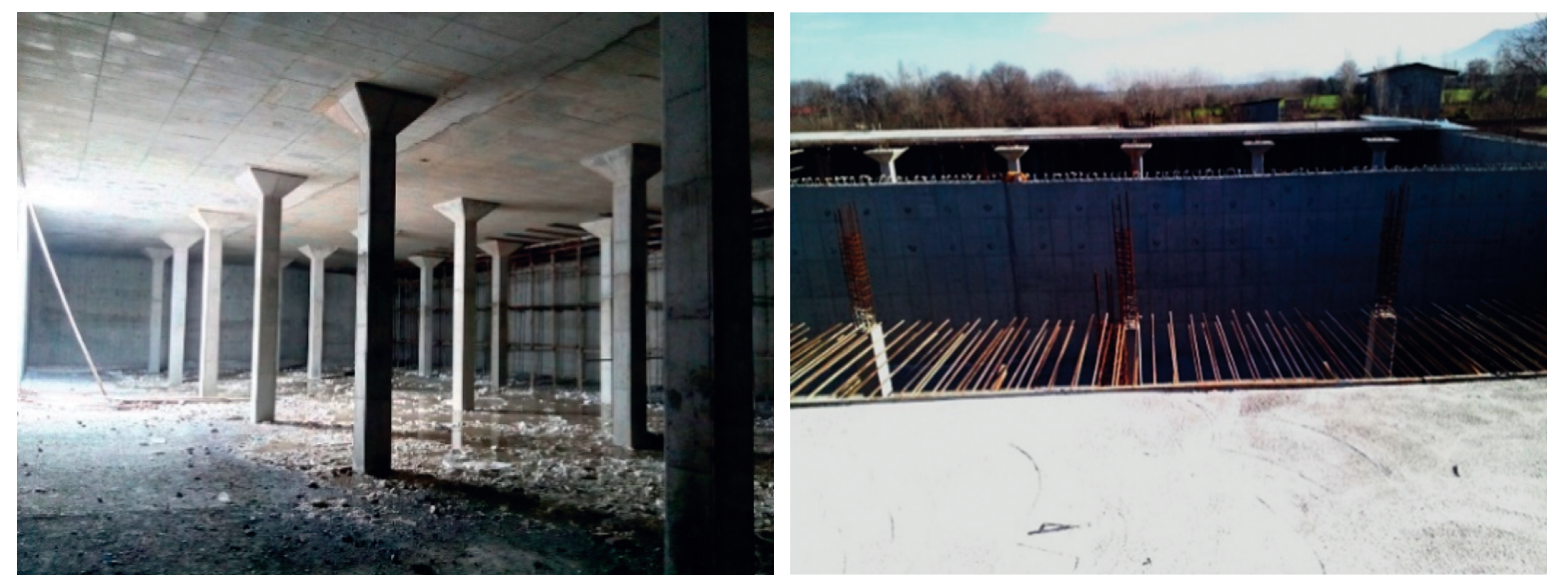

FIGURE 1: Concrete surface tank with $5000 \mathrm{~m}^{3}$ volume in Kermanshah.

among the first researchers who had done many studies on dynamic behaviour of the water tanks. He In 1954, modeled a cubic and cylindrical fluid storage tank [1]. He also calculated the hydrodynamic pressure distributed by the fluid and the height of the surface waves caused by the horizontal vibrations using a mass-spring dynamic system [2]. Haron and Housner developed a single ring model using finite element model and integral boarder assumption for the fluid model and the crust around it as a reliable method for dynamic analysis of the flexible tanks [3]. Haron (1992) further studied an experimental model for the tanks established on the soil given to the soil-tank interaction effect. Then, numerical methods, especially finite element was used broadly to model carefully fluid behaviour in addition to the tank behaviour. Bernal [4] studied seismic response of the cylindrical tanks on the earth under the earthquake record using three-dimensional finite element models [5].

Heavy damages have been reported due to the frequent and strong earthquakes such as Niigata (1934), Alaska (1964), Parkfield (1966), Imperial City (1979), Coalinga (1983), Northridge (1994), Cocalo (1999), and Beijing (2001) that some of them have been reported by Adlparvar et al. [6], Mohammadi et al. [7], and Ibarra and Krawinkler [8]. Concrete tanks are damaging greatly too. For instance, so many concrete tanks are broken when they are rising in height or are damaged strongly in Chili earthquake in 1960 and Beijing earthquake in 2001. In addition, big and intense damages were imposed to rectangular tanks under the earth which has been reported by Kim and Kim [9] in Kobe earthquake.

After that, Husner has formulated ideas in 1957 [10] and 1963 [11] which are usually used in the civil engineering course to meet seismic response of the liquid in rigid and flexible rectangular and cylindrical tanks. This liquid is considered as incompressible and inviscid. In this method, hydrodynamic pressure resulted from seismic excitation has been divided to the thermal and impact components using approximate value for lump mass. Impact pressure is generated by a part of the liquid or tank acceleration while thermal pressure is generated by a part of the liquid oscillation in the tank. Accordingly, Husner has decreased these pressures by expanding simplified statements or lump mass model. Lump mass from impact pressure point of view is connected intensively to the tank's wall but lump mass from thermal pressure point of view is connected to the wall's tank using the sources. This model with some changes is approved in many current codes and standards [12].

\section{Methods and Materials}

2.1. Fluid-Structure Interaction (FSI). Fluid-structure interaction (FSI) is the interaction of some movable or deformable structures with an internal or surrounding fluid flow. In this article, contact element is used to introduce interaction. In this element, all forces are transferred in two tangential and vertical directions from a surface to another one. Tangential behaviour (tangential components) includes relative motion (slide) of the surfaces and if shear stresses are existed as the effect of the friction. To determine whether transferable shear forces between the surfaces are in contact with each other, analysis needs calculation of the friction forces which is resisted against relative slide between the surfaces. One of the common models in defining tangential components of the interaction between the contact surfaces is Coulomb friction model. It determines the friction behaviour between the contact surfaces using a friction coefficient $\mu$. Default friction coefficient is zero. Tangential displacement will be zero to the extent which surface tension does not exceed a critical value for shear stress. Shear stress is determined as the following equation [13]:

$$
\tau_{\text {crit }}=\mu \rho,
$$

in which $\mu$ is the friction coefficient and $\rho$ is the contact pressure between two surfaces. This equitation gained limit value for shear stress for the participated surfaces in the contact. Contact surfaces will not have any slide on each other up to the time when shear stress between them becomes equal to the limited friction shear stress; for the most surfaces, $\mu$ is usually less than 1 . To define water-structure interaction from Euler-Lagrange view with optional mesh 
displacement has been used in which intense transformations of the mesh are limited and generation of the new meshes is allowed at every moment in the transformed points. Indeed in this approach, it is assumed that the displacement of the mesh nodes is independent of the modelled materials and indeed can flux inside the mesh. One of the main advantages of this method is that it provides the possibility of local amendment of the mesh without changing the whole mesh. On the other hand, it can be said that investigated materials are fixed but its mesh is changing every moment and the solution is transferred from the first to the second unit. Euler relation (relation (2)) is written as below just by taking hydrodynamic pressure into account from the following equation [14]:

$$
\rho \frac{D \vec{V}}{D t}=-\vec{\nabla} p .
$$

Therefore, prominent assumptions on Euler equation (in the third type interaction) are small displacements, nonrotating motion, and ignoring viscosity (adhesion effect). Given to the abovementioned three assumptions, prominent equation on the tank's water is the same as Euler equation. By taking into account the hydrodynamic pressure, equation (3) can be extracted [15]:

$$
\rho \frac{D \vec{V}}{D t}=-\vec{\nabla} p \longrightarrow \rho \frac{\partial \vec{V}}{\partial t}+\rho(\vec{\nabla} \cdot \vec{V}) \vec{V}=-\vec{\nabla} p .
$$

Given that displacement range and speed in the third type interaction is very limited, then the second statement in the left hand of the equation can be ignored. Therefore, the final form of the prominent Euler's equation of motion is obtained as the following equation [16]:

$$
\rho \frac{\partial \vec{V}}{\partial t}=-\vec{\nabla} p
$$

2.2. Soil-Structure Interaction (SSI). The concept of structure-soil-structure dynamic interaction was introduced, and the research methods were discussed [17]. Based on several documents, a systematic summary of the history and status of the structure-soil-structure dynamic interaction research that considers adjacent structures was proposed as a reference for researchers [18]. The most common way to solve soil-structure interaction problem is analysis according to substructure method. In this approach, linear problem of soil-structure interaction is divided into a series of subproblems and then the results are combined using superposition principle. In the approach of the separation and dividing of the substructures [19], the whole system of soilstructure is represented in Figure 1 which is divided into three substructures. I substructure includes the free field of the site, II substructure includes excavated soil volume, and III substructure includes surface structure and its foundation. In the method of separation of the substructures, it is assumed that the soil-structure interaction is occurred only in the common boarders of the substructures, contact surface, or soil. Substructures' equation of motion represented in Figure 1 can be written in a matrix form of the following equation [20]:

$$
[M]\{\tilde{\ddot{u}}\}+[K]\{\tilde{u}\}=\{\hat{Q}\} .
$$

For imposed harmonic excitation, with $\omega$ frequency, load vector and displacement can be written as the following equations [21]:

$$
\begin{aligned}
& \{\widehat{Q}\}=\{Q\} \exp (i \omega t), \\
& \{\hat{u}\}=\{u\} \exp (i \omega t) .
\end{aligned}
$$

When $\{Q\}$ and $\{u\}$ are integrated force vector and displacement in $\omega$ frequency. Therefore, for each frequency, the equation of motion will be as the following equations [22]:

$$
\begin{aligned}
{[C]\{Q\} } & =\{Q\}, \\
\{\hat{u}\} & =\{u\} \exp (i \omega t) .
\end{aligned}
$$

The equation of motion for the soil-structure interaction system is separated as the following equation [23]:

$$
\left[\begin{array}{ccc}
C_{i i}^{I I I}-C_{i i}^{I I}+X_{i i} & -C_{i w}^{I I} & C_{i s}^{I I} \\
-C_{w i}^{I I} & -C_{w w}^{I I} & 0 \\
-C_{s i}^{I I} & 0 & C_{s s}^{I I}
\end{array}\right]\left\{\begin{array}{c}
u_{i} \\
u_{w} \\
u_{s}
\end{array}\right\}=\left\{\begin{array}{c}
X_{i i} u \\
0 \\
0
\end{array}\right\},
$$

where indices I, II, and III are related to three substructures and $i, w$, and $s$ indices are related to degrees of freedom corresponding to the available nodes in the border between the soil and structure, excavated soil volume, and surface structure, respectively (Figure 2) [25].

At the left hand side of the equation, the combined dynamic stiffness matrix related to the frequency indicated simply that according to the above category, the stiffness matrix of the excavated soil is subtracted from the dynamic stiffness of the structure and the free field. Matrix related to frequency $\left\lfloor X_{f f}\right\rfloor$ is called impedance matrix which is obtained from I substructure transformer. $\left\{u_{i}^{\prime}\right\}$ or $\left\{u_{f}^{\prime}\right\}$ vector is obtained from motion of the site's free field at the interaction points indicated in I substructure. The DOF interactions is considered between the site model and the horizontal layers during the impedance and external load vector calculations [4]. Also, the assumption of the linear transformation changes inside the layer can be divided into the Rayleigh and love wave as the algebraic eigenvalue. Using the separated soil model, eigenvalue equation for the motion of the Rayleigh wave can be written as the following equation [26]:

$$
\left([A] K^{2}+i[B] K+[G]-\omega^{2}[M]\right)\{V\}=0 .
$$

In this model at each border between two layers, two degrees of freedom are existed then every $n$ layer system will have $2 n$ degree of freedom. At the previous equation, $\omega$ and $k$ are angular frequency of the mode vibration and eigenvalue, respectively, and $\{V\}$ is the component-wise $2 n$ eigenvector. Dimensions of the $[A],[B],[G]$, and $[M]$ matrices are 


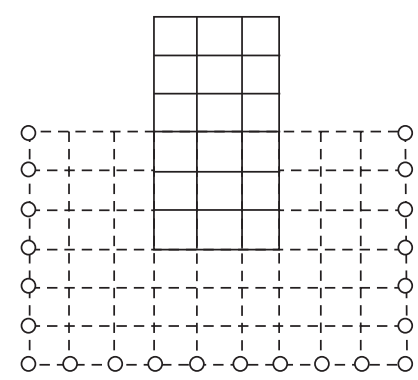

(a)

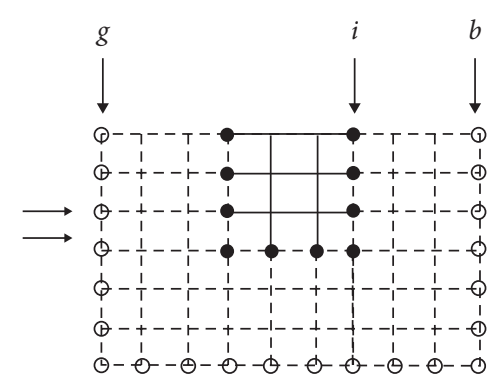

(b)

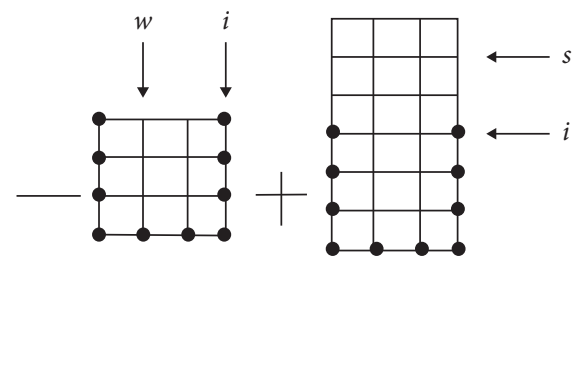

(c) (d)

Figure 2: Separation of the substructures to simplify calculations [24]. (a) Total system. (b) Substructure 1: free field. (c) Substructure 2: excavated soil. (d) Substructure 3: build structure.

$2 n \times 2 n$ and these matrices are gained by summing related matrices of the sublayers. Considering the $h_{j}$ as the depth, $R o_{j}$ as the density, $G_{j}$ as the shear modulus and land $a_{\mathrm{j}}$ as the constant of the $j^{\text {th }}$ layer, then the matrix can be expressed as follows [27]:

$$
\begin{aligned}
& {\left[A_{j}\right]=\frac{h_{j}}{6}\left[\begin{array}{cccc}
2\left(\lambda_{j}+2 G_{j}\right) & 0 & \left(\lambda_{j}+2 G_{j}\right) & 0 \\
0 & 2 G_{j} & 0 & G_{j} \\
\left(\lambda_{j}+2 G_{j}\right) & 0 & 2\left(\lambda_{j}+2 G_{j}\right) & 0 \\
0 & G_{j} & 0 & 2 G_{j}
\end{array}\right]} \\
& {\left[B_{j}\right]=\frac{1}{6}\left[\begin{array}{cccc}
0 & -\left(\lambda_{j}-G_{j}\right) & 0 & \left(\lambda_{j}+G_{j}\right) \\
\left(\lambda_{j}-G_{j}\right) & 0 & \left(\lambda_{j}+G_{j}\right) & 0 \\
0 & -\left(\lambda_{j}+G_{j}\right) & 0 & \left(\lambda_{j}-G_{j}\right) \\
-\left(\lambda_{j}+G_{j}\right) & 0 & -\left(\lambda_{j}-G_{j}\right) & 0
\end{array}\right],} \\
& {\left[G_{j}\right]=\frac{1}{h_{j}}\left[\begin{array}{cccc}
G_{j} & 0 & G_{j} & 0 \\
0 & \left(\lambda_{j}+2 G_{j}\right) & 0 & -\left(\lambda_{j}-2 G_{j}\right) \\
-G_{j} & 0 & G_{j} & 0 \\
0 & -\left(\lambda_{j}-2 G_{j}\right) & 0 & \left(\lambda_{j}+2 G_{j}\right)
\end{array}\right]} \\
& {\left[M_{j}\right]^{[l]}=\frac{\rho_{j} h_{j}}{6}\left[\begin{array}{llll}
0 & 0 & 0 & 0 \\
0 & 1 & 0 & 0 \\
0 & 0 & 1 & 0 \\
0 & 0 & 0 & 1
\end{array}\right]\left[M_{j}\right]^{[c]}=\frac{\rho_{j} h_{j}}{6}\left[\begin{array}{llll}
2 & 0 & 1 & 0 \\
0 & 2 & 0 & 1 \\
1 & 0 & 2 & 0 \\
0 & 1 & 0 & 2
\end{array}\right],}
\end{aligned}
$$

where $\left[M_{j}\right]^{[c]}$ and $\left[M_{j}\right]^{[l]}$ are the continuous mass and lumped mass matrices. Using numerical techniques proposed by Vas, eigenvalue equation of equation (14) can be solved. At the separation of the substructure method, SSI system motion equations, including $\left[X_{f f}\right]$ impedance matrix, are the same as shown in equation (15). In this method, impedance matrix is calculated just for border nodes ( $\mathrm{i}$ nodes in Figure 2). In each frequency, the impedance matrix analysis is calculated by dynamic softness matrix. In the three-dimensional problems, the problem of estimating dynamic softness matrix is decreased to the problem of finding the response of horizontal layer system to the loading at the border of the layers. After the calculation of the elements of the mass and stiffness matrices, the motion equation will be as the following equation [28]:

$$
\left[\begin{array}{cc}
C_{C C} & C_{C P} \\
C_{P C} & C_{P P}+R
\end{array}\right]\left\{\begin{array}{c}
u_{c} \\
u_{p}
\end{array}\right\}=\left\{\begin{array}{c}
Q_{c} \\
0
\end{array}\right\}
$$

in which $C$ is the dynamic stiffness matrix $\left(C=K-\omega^{2} M\right)$ and $R$ is the impedance matrix of the energy absorbing borders. $p$ and $c$ indices are related to the degrees of freedom on the border line and circumference of the modulus $u_{c}$ and $u_{p}$ is the amount of the correspondent displacements. Displacement of the external nodes of the model $\left(r>r_{0}\right)$ is obtained by the following equation [29]:

$$
\{u(r)\}_{m}=[w(r)]_{m}\{\Delta\}_{m} .
$$

The $m$ index is related to the Fourier harmonic degree and the vector below modal participation coefficient, related to $3 n$, is the transformational mode of the $n$ layer soil system:

$$
\{\Delta\}_{m}^{T}=\left\langle\alpha_{1}, \alpha_{2}, \ldots, \alpha_{3 n}\right\rangle
$$

and $[W(r)]_{m}$ matrix is a $3 n \times 3 n$ matrix which is a function of radial distance from the model axis, eigenvalue, eigenvector, and Hankel function of the second kind of the $m^{\text {th }}$ degree [30]. Having modular participation vector, equation (11) is applied to calculate displacement, at each point with radial distance $r$ from the axis of the model. Dynamic softness matrix at each analysis frequency is a $3 i \times 3 i$ matrix for a system with $i$ interactional node at the environment of the soil-free field.

\section{Numerical Modelling}

In this study, using limited components software, a conducted tank in reality is studied dynamically and three-dimensional. Then, one of the surface tanks of the 
Kermanshah is selected and the solid element is used for modelling [31].

3.1. Mechanical Characteristics of the Material. To state the behaviour of the steel, nonlinear behaviour with kinematic hardening is used. Plastic behaviour of the model is based on von Mises yield criterion and is selected based on stressstrain graph ST37. Given to Figure 3, Young's modulus and Poisson's ratio are considered as $2 \times 10^{6} \mathrm{~kg} / \mathrm{cm}^{2}$ and 0.3 , respectively [32].

Behaviour al model which has been taken into account for soil in this article is the Drucker-Prager model in which identical theory of elasticity is used for the elastic behaviour and hardening Drucker-Prager plasticity model is used for plasticity behaviour. This model is known as the nonlinear model of the soil behaviour using modified Drucker-Prager plasticity model (cap) in which yield surface, flow rule, and hardening rule should be taken into account too [33]. Drucker-Prager surface of rapture is obtained from the below relation [34]:

$$
\begin{aligned}
& F_{s}=t-p \tan \beta-d=0, \\
& F_{s}=t-p \tan \beta-d=0,
\end{aligned}
$$

in which $\beta\left(\theta, f_{i}\right)$ and $d\left(\theta, f_{i}\right)$ represented friction angle of the material and its adhesion, respectively, and can be affected by temperature, $\theta$, and other defined factors. $t$ and $P$ are the amount of deviator stress and equivalent compressive stress, respectively [33].

To study the effect of the soil type in soil-structure interaction, three kinds of soil, soft, moderate, and hard, are used and obtained results are compared with each other. Characteristics of the soil used in the models are indicated in Table 1 [35].

In Table $1, \varphi C$ and $\psi$ are soil's internal friction angle, adhesion, and soil dilation angle, respectively. This model is stated using nonlinear behaviour in the compressive area and linear behaviour in the tensile area [33]. Meanwhile, Table 2 is used to introduce concrete through linear behaviour and Figure 4 through nonlinear behaviour [36].

To introduce the fluid inside the tank water with density $1000 \mathrm{~kg} / \mathrm{m}^{3}$, dynamic viscosity $0.0013 \mathrm{~N} \cdot \mathrm{sec} / \mathrm{m}^{2}$ and shear wave velocity in water $1400 \mathrm{~m} / \mathrm{s}$ have been taken into account. The selected tank is located in Jungle Street in Kermanshah. Total dimensions of this tank are $50 * 40$ with nearly $4 \mathrm{~m}$ height. The twin tank is established to supply potable water of Kermanshah in 1395.

3.2. Geometrical Specifications of the Model. This tank includes 36 columns with $3 \mathrm{~m}$ height and $40 * 40 \mathrm{~cm} \mathrm{di-}$ mensions and $60 * 60 \mathrm{~cm}$ crown. The tank includes foundation, surrounding walls and middle wall, columns, and ceiling (Figure 5).

To mesh the geometric model of the tank, its columns and walls, hexagonal 8-node elements have been used; the final model is shown in Figure 6.
3.3. Loading. For doing dynamic analysis, seismic excitation is imposed through low borders as a time history of the displacement on the model used. These excitations are transient and in the direction of the $X$ axis (Figure 7). Meanwhile, since just the effect of the influential parameters on the response of the structure has been investigated, then seismic load is imposed only in the horizontal direction on the soil mass [37].

\section{Results Analysis}

So many factors are affecting on seismic response of the surface tanks including soil type, soil's modulus of elasticity, angle of friction between the structure (foundation) and soil, height of the fluid inside the tank, and flexibility of the tank's wall. In this study, it is tried to study how the first few factors are influential [38].

4.1. The Effect of the Soil Type. Time history of the horizontal displacement in the direction of the load imposed above the tank for different kinds of the soil is shown in Figures 8 and 9. Given to this diagram, it can be seen that the horizontal displacement on the tank is more in the soft soil than moderate and hard soils. Indeed, the lower the shear waves velocity in the soil, the greater the effect of soil-structure interaction on the analysis and the softer the structure and the more displacement on the tank will occur. Increasing the effect of the soil-structure interaction raises damping of the structure, decreases input displacement, and decreases frequency of the structure (increased period of the structure and therefore its softening). The effect of the soil type in the shear stress generated at the foot of the tank (at the connection site of the tank with foundation) is represented in Figures 8 and 9. As it can be seen, stress on the tank foot in the soft soil is less than moderate and hard soil. As it is said before, by reducing the shear wave velocity in the soil, the effect of soil-structure interaction increases and, as a result, the stress decreases (stress decreases as the effect of seismic input decreased and damping increased).

4.2. The Effect of the Soil Density. With decreasing the soil density, maximum displacement increases above the tank. With decreasing density by $15 \%$, the soil becomes softer and the soil-structure interactional effect increases and therefore the structure becomes softer and maximum displacement increases by nearly $17 \%$. Maximum shear stress at the foot tank can be seen in Figures 10 and 11. By decreasing soil density by $15 \%$, soil becomes softer and interactional effect and maximum tension decrease.

4.3. The Effect of the Soil Modulus of Elasticity. As it can be seen in Figures 12 and 13 with 30\% decrease in the soil modulus of elasticity, maximum displacement increases $50 \%$ above the tank. With decreasing modulus of elasticity by $30 \%$, the soil becomes softer and soil-structure interactional effect increases and therefore the structure becomes softer and maximum displacement increases by $16 \%$. 


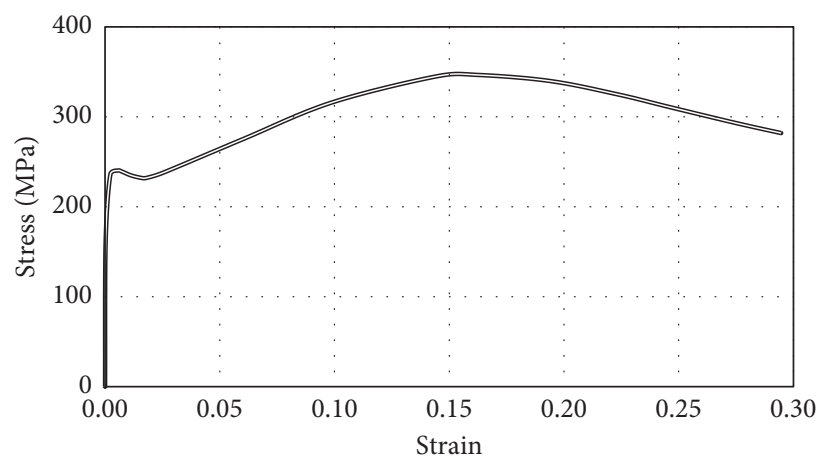

FIGURE 3: Steels' behaviour al nonlinear model.

TABLE 1: Characteristics of the soil used in the model.

\begin{tabular}{lccccc}
\hline Soil type & $\rho\left(\mathrm{kg} / \mathrm{m}^{3}\right)$ & $E(\mathrm{MPa})$ & $v$ & $\varphi$ & $\mathrm{C}\left(\mathrm{N} / \mathrm{m}^{2}\right)$ \\
\hline Hard soil & 2000 & 10 & 0.4 & 35 & 0.8 \\
Moderate soil & 1700 & 7 & 0.4 & 35 & 0.8 \\
Soft soil & 1500 & 5 & 0.4 & 35 & 4.81 \\
\hline
\end{tabular}

TABle 2: Characteristics of the concrete used in the tank and foundation.

\begin{tabular}{lcc}
\hline$\rho\left(\mathrm{kg} / \mathrm{m}^{3}\right)$ & $v$ & $E(\mathrm{GPa})$ \\
\hline 2450 & 0.2 & 19.7 \\
\hline
\end{tabular}

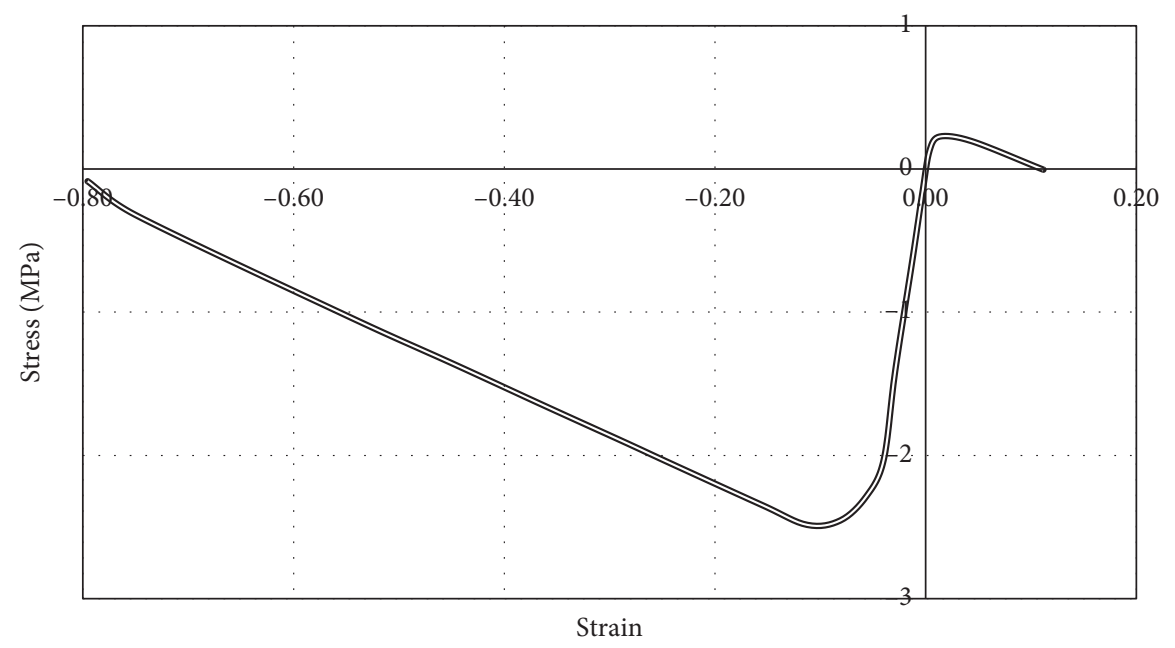

FIGURE 4: Compressive and tensile behaviour of the concrete [33].

4.4. The Effect of the Friction Coefficient between the Soil and Foundation of the Tank. To study the interactional effect on the seismic response of the surface tank, friction coefficients between the foundation and soil surfaces are considered as $0.1,0.2,0.4$, and 0.7 . It is seen that with increasing friction coefficient between the soil and foundation surfaces, maximum displacement above the tank increases. Indeed, with increasing the friction coefficient between the soil and foundation surfaces, slip between the surfaces decreases and input displacement to the tank increases and therefore maximum displacement increases above the tank. On the other hand, with increasing the soil stiffness by nearly $15 \%$, maximum amounts of the displacement decreases by $15 \%$ too (Figure 14).

4.5. The Effect of the Soil's Angle of the Internal Friction Amount. With increasing internal angle friction of the soil, maximum displacement decreases too. With the effect of the internal angle of the friction of the soil by 6 times, involvement between the soil granules increases and interactional effect decreases and therefore maximum 


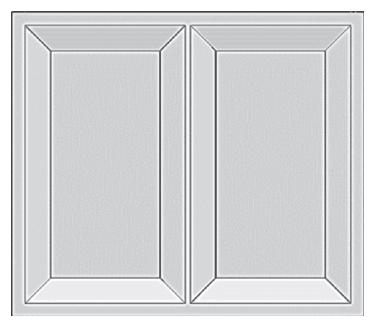

Foundation

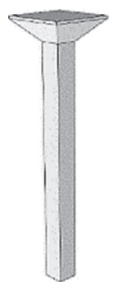

Column

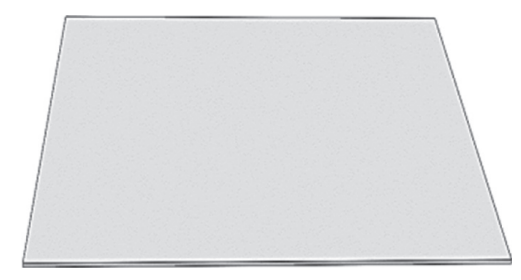

Ceiling

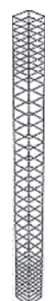

Column armature networking

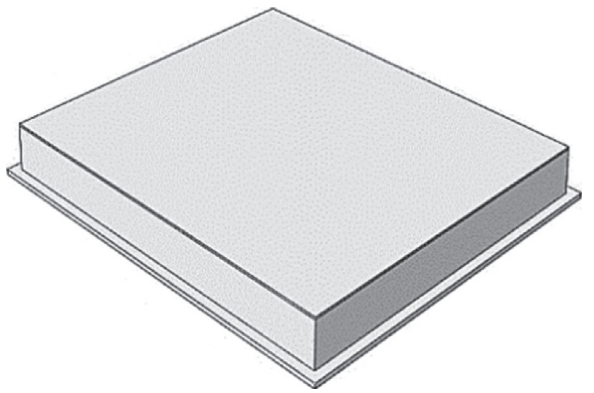

Total geometrical figure of the tank

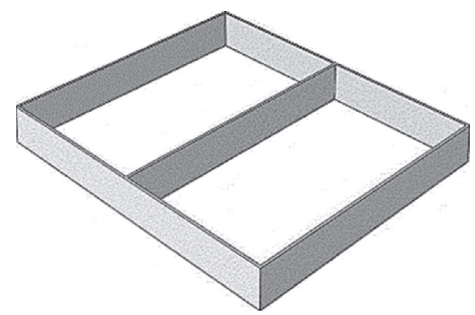

Walls

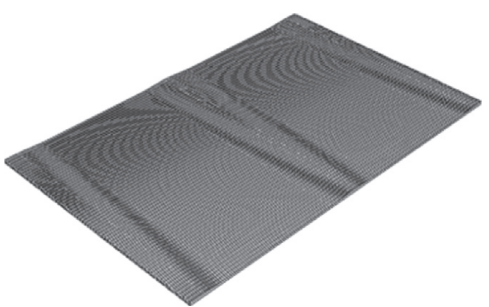

Foundation armature networking

Figure 5: Geometrical scheme of the finite components model of the surface tank.
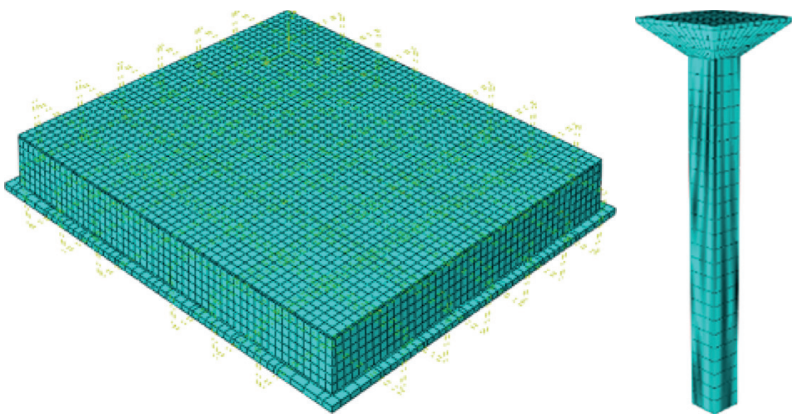

Figure 6: Numerical meshing model.

displacement above the tank decreases intangibly less than 1\% (Figure 15).

4.6. The Effect of the Fluid (Water) Height inside the Tank and Turbulence. To study the effect of the height inside the tank on its seismic response, the heights of the water inside the tank are considered as 2, 5, and 7 and displacement above the tank and stress at the foot of the tank have been calculated in the moderate soil. Figure 16 indicated the time history of the shear stress on the foot of the tank in three states of the water height inside the tank and in moderate soil. With increasing the water height inside the tank by $2 \mathrm{~m}$, hydrodynamic pressure of the water imposed to the wall of the tank increases and, on the other hand, led to increase in mass of the tank and therefore greater seismic force is imposed to the tank and then stress on the foot of the tank decreases by nearly $20 \%$.

To study turbulence effect, two samples in turbulence and without turbulence states are modelling whose results are compared in Figure 17. Shear stress at the foot of the tank by taking turbulence of the water into account will be nearly 


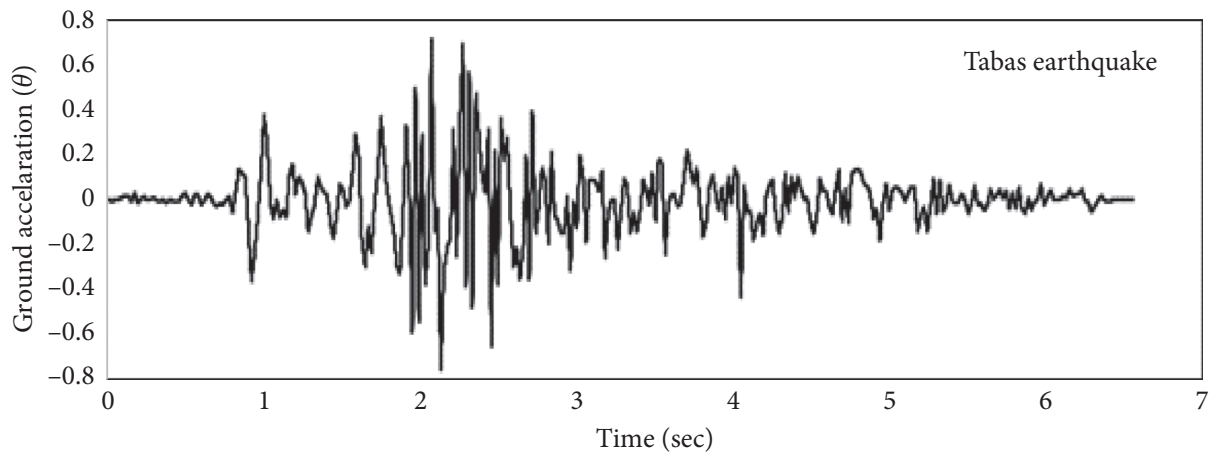

Figure 7: Accelerograph of the Tabas earthquake.

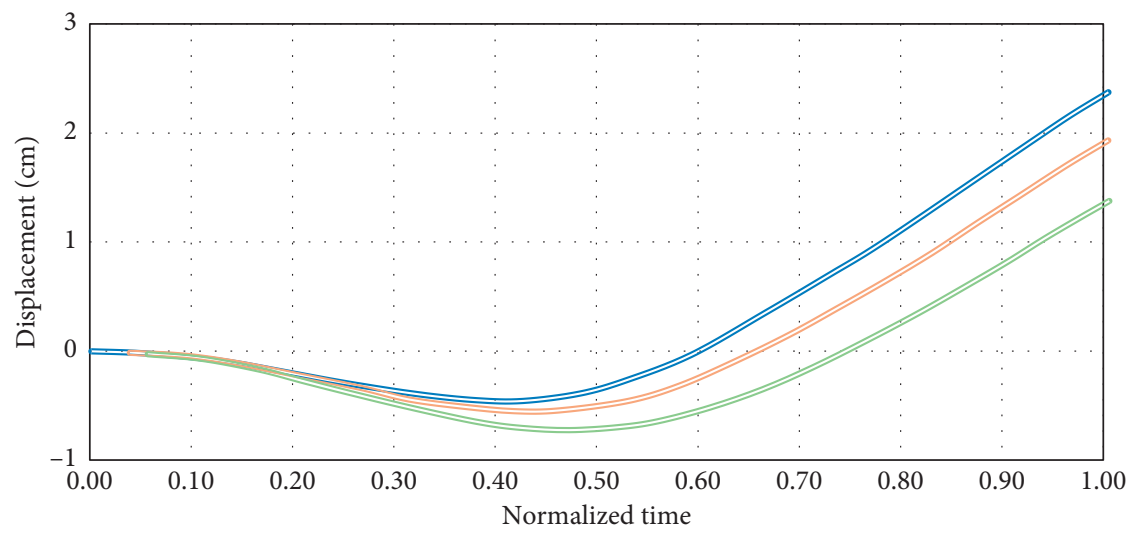

Soft soil

Moderate soil

Hard soil

FIGURE 8: Time history of the horizontal displacement above the tank.

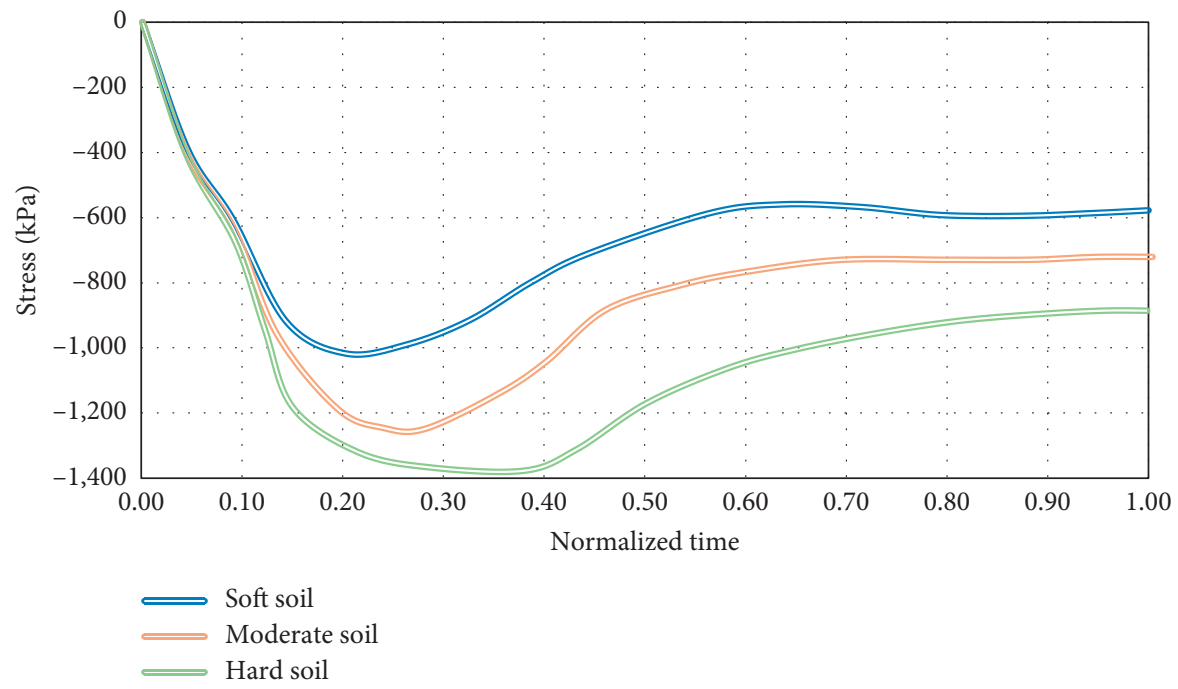

FIGURE 9: Time history of the shear stress in the connection site of the tank with foundation.

$30 \%$ higher than base stress from the size point of view. The response variation rates must be considered to estimate the parameters effects on reservoir tanks behavior. Then, a parameter as $\lambda$ is defined which is obtained through the following relation: $\lambda=$ absolute (quotient of the changes percent of the responses to the changes of the given parameter).

Figure 18 indicated that the structure response is more sensitive to the changes of the density and soil's modulus of elasticity and changes of the friction angle between the soil 


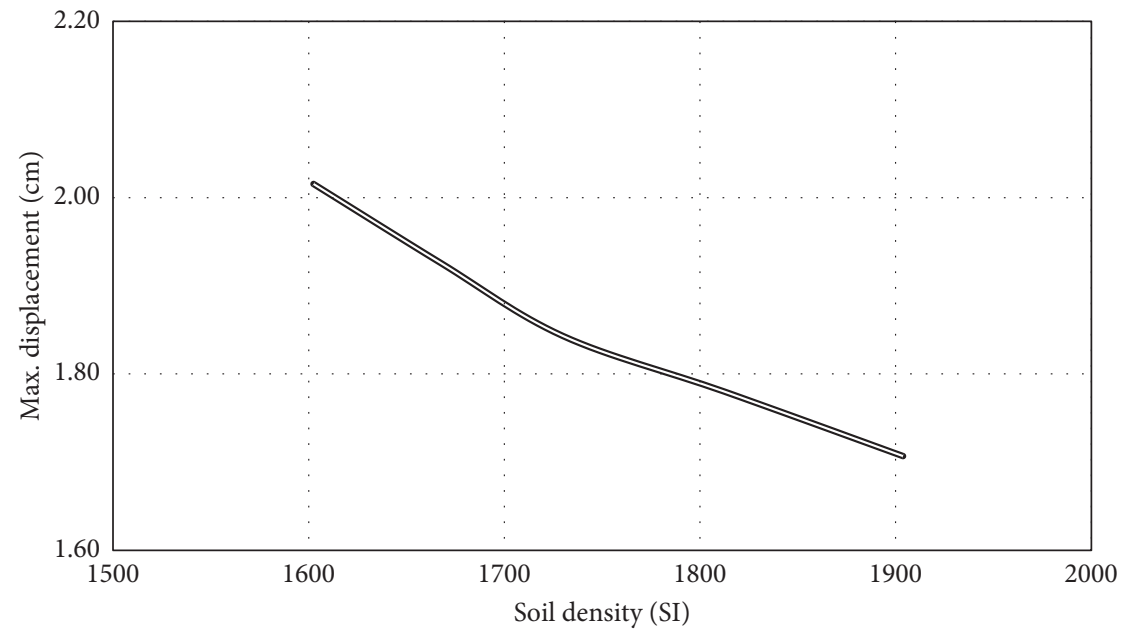

FIGURE 10: Maximum changes of the displacement above the tanl in terms of the soil density.

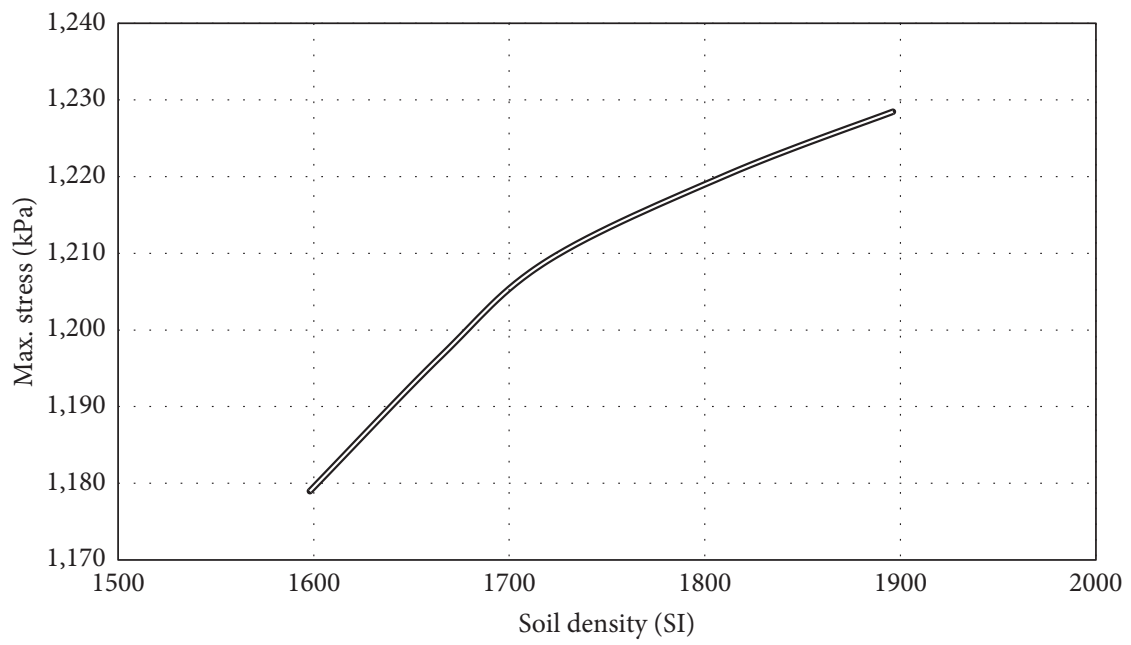

Figure 11: Maximum changes of the pressure on the foot of the tank in terms of the soil density.

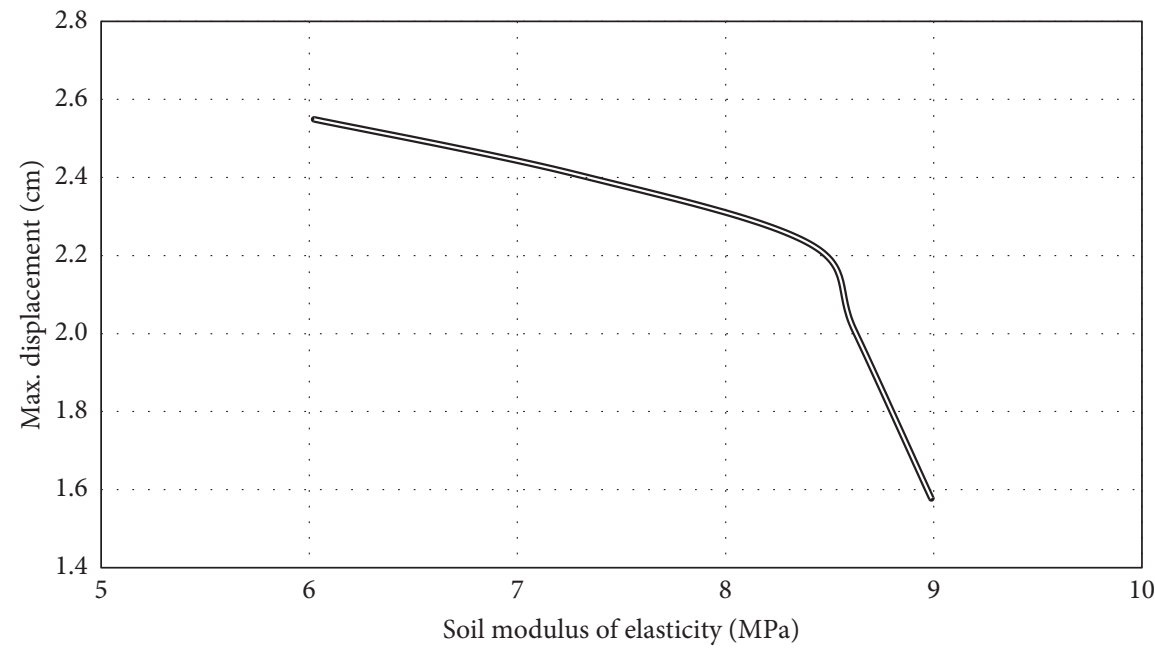

FIGURE 12: Maximum changes of the displacement above the tank in terms of the soil modulus of elasticity. 


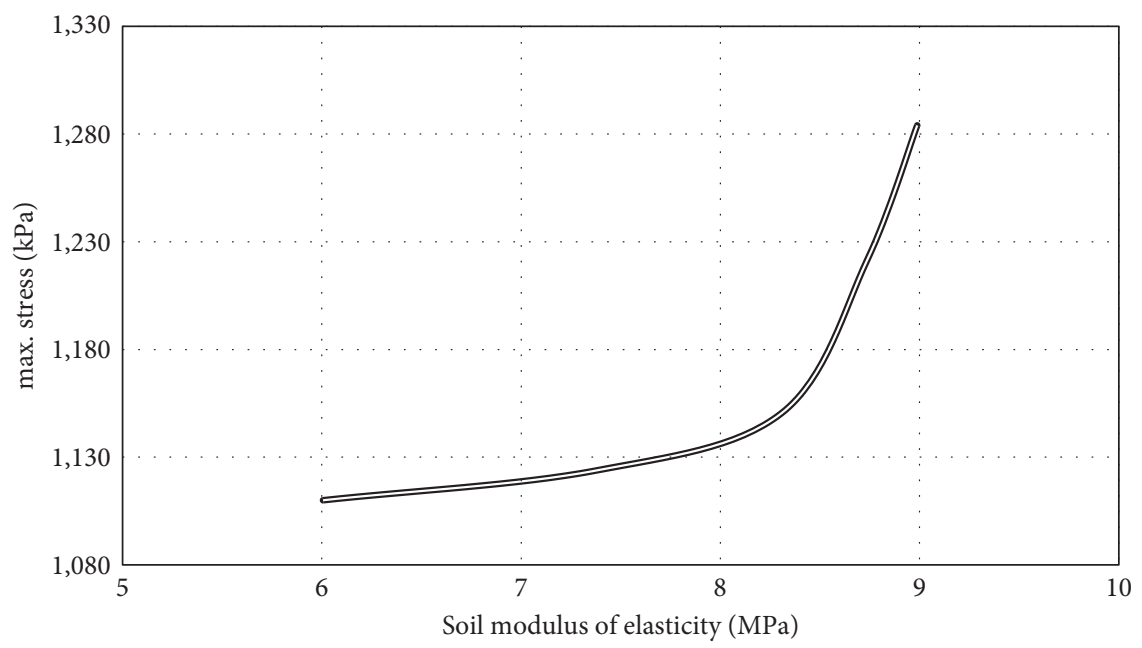

FIgURE 13: Maximum changes of the stress on the foot of the tank in terms of the soil modulus of elasticity.

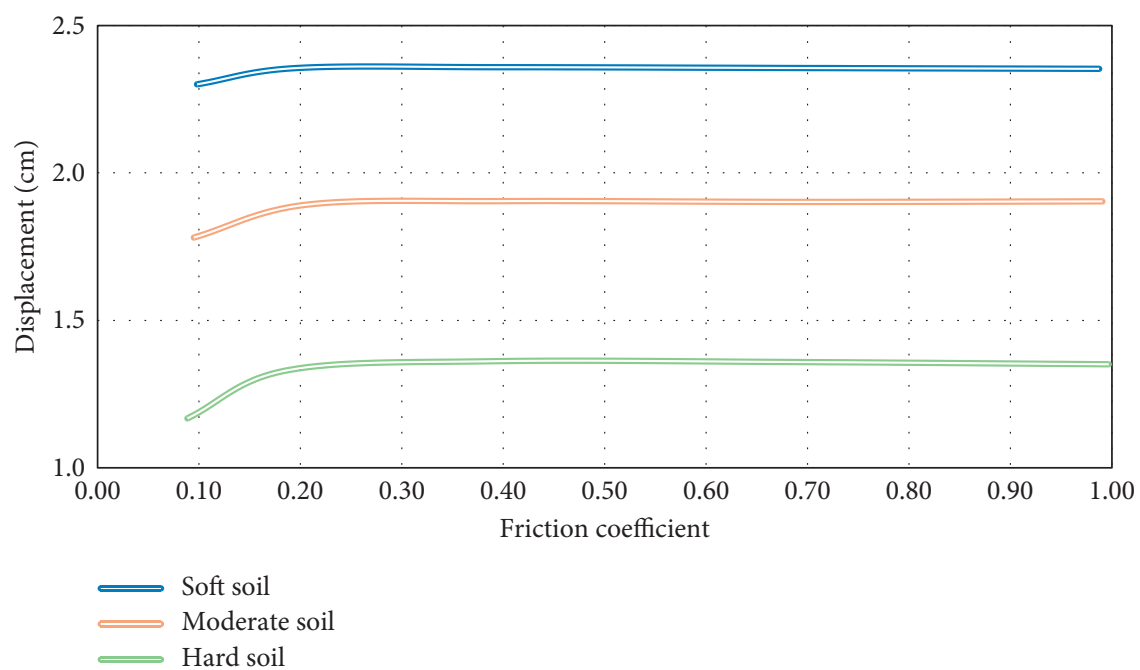

FIGURE 14: Diagram of the maximum displacement changes above the tank in terms of the friction coefficient.

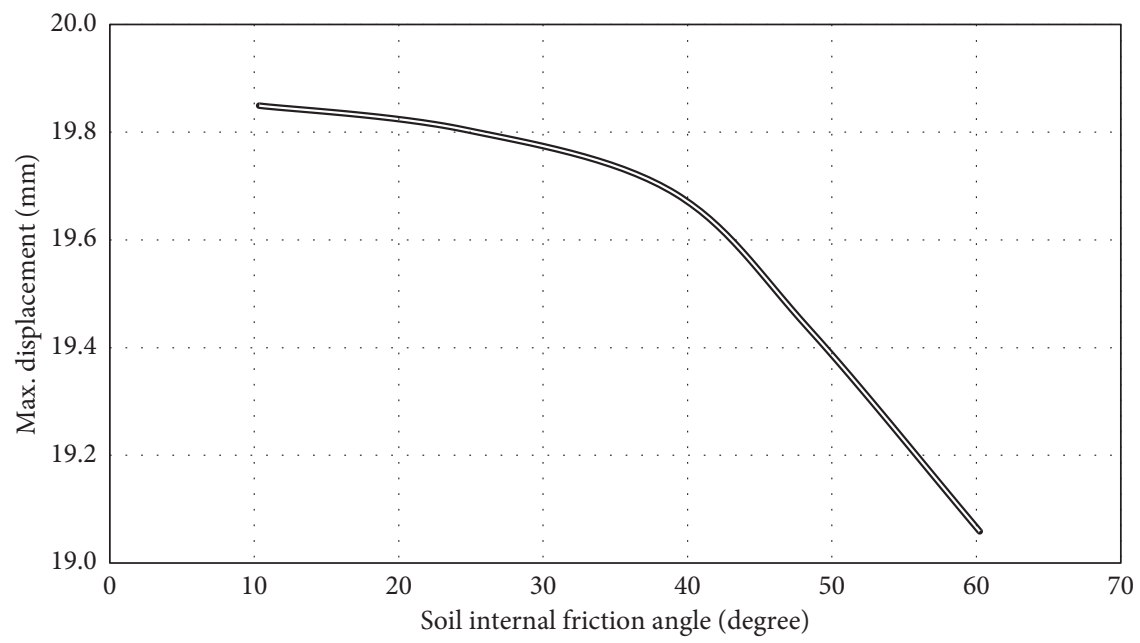

FIgURE 15: Maximum changes of the displacement above the tank in terms of the internal friction angle of the soil. 


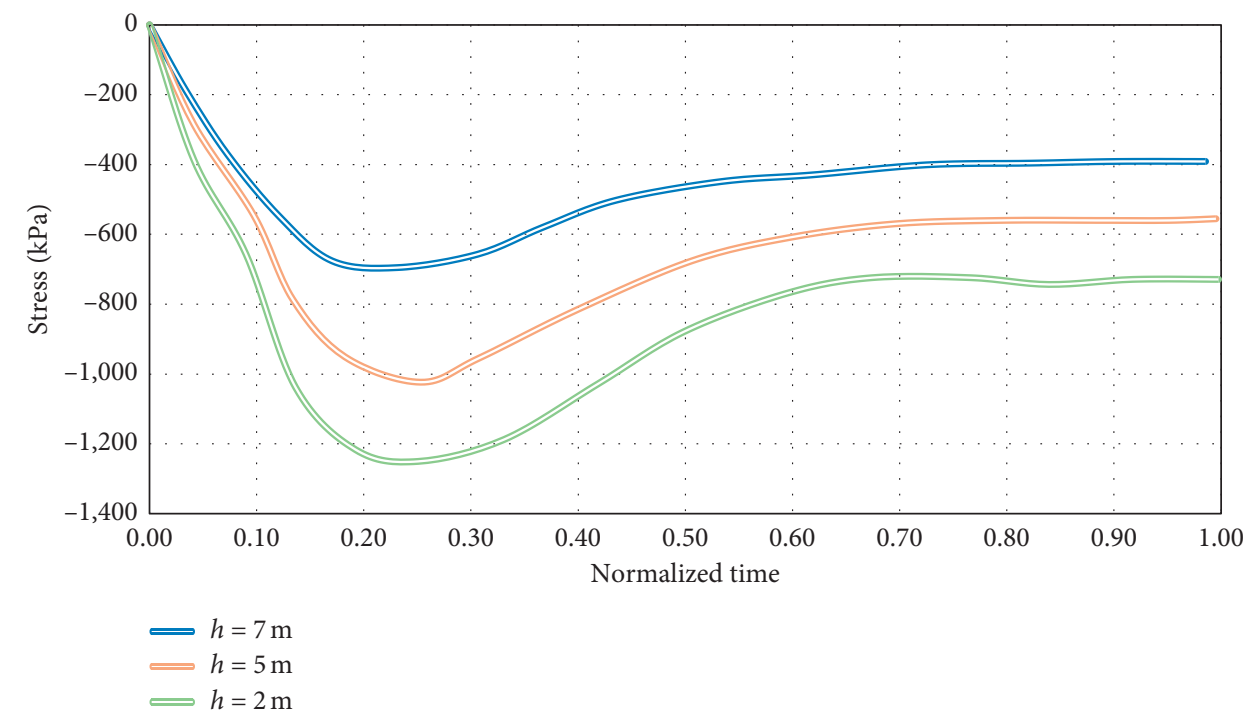

FIGURE 16: diagram of the time history of the shear stress at the foot of the tank in three states of the water height inside the tank.

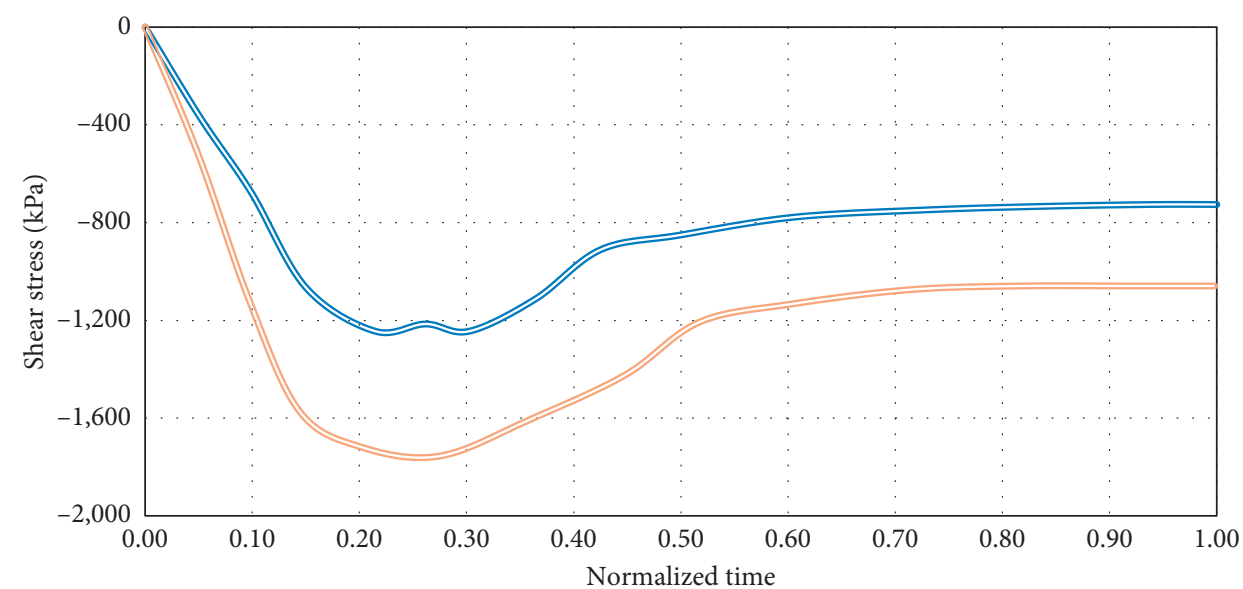

Neglecting sloshing

Considering sloshing

Figure 17: Diagram of the time history of the shear stress at the foot of the tank to study turbulence effect.

1

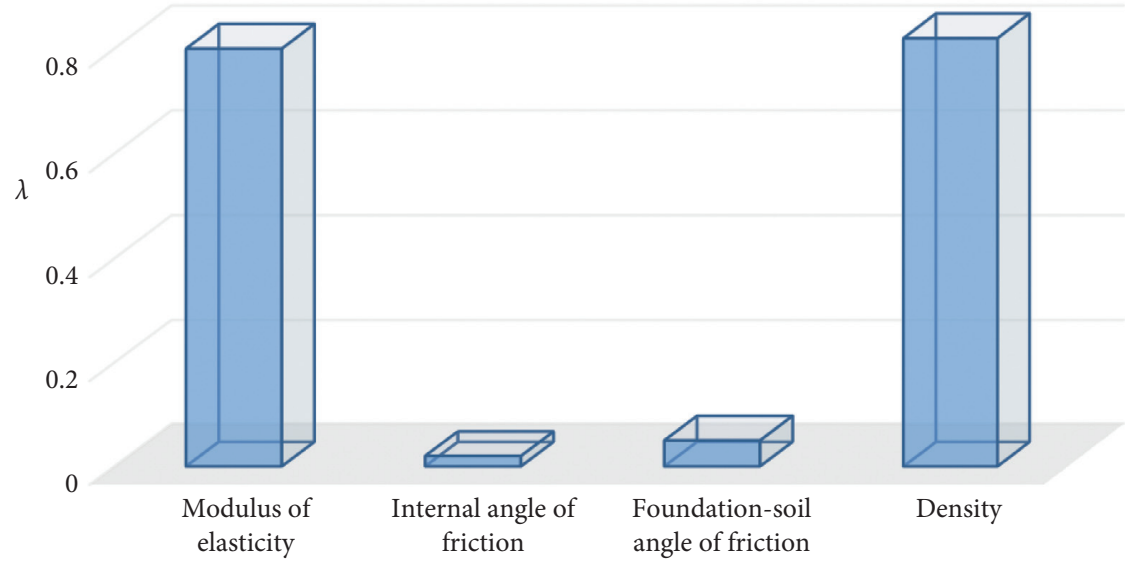

FIGURE 18: Sensitivity of the tank response to the given parameters. 
and foundation surfaces and internal friction angle do not have tangible effect on response.

\section{Conclusion}

By decreasing soil density, maximum displacement increases above the tank. With 15\% decrease in density, the soil becomes softer and soil-structure interactional effect increases and therefore the structure becomes softer and maximum displacement increases by nearly $17 \%$. With $30 \%$ decrease in the soil modulus of elasticity, maximum displacement above the tank increases nearly 50\%. With decreasing modulus of elasticity to $30 \%$, the soil becomes softer and soil-structure interaction increases and therefore the structure becomes softer and maximum displacement increases by $16 \%$. To study the interactional effect on the seismic response of the surface tank, friction coefficients between the foundation and soil surfaces are considered as $0.1,0.2,0.4$, and 0.7 , and shear stress at the foot of the tank by taking turbulence of the water into account will be nearly $30 \%$ higher than base stress. With increasing friction coefficient between the soil and foundation surfaces by $15 \%$, maximum displacement above the tank increases $15 \%$ too. With increasing internal angle friction of the soil, maximum displacement above the tank decreases. The obtained results shows that the internal friction angle has negligible effect on the tank displacement because its 6 time increase caused only 1\% increase in the maximum displacement of it. The most important results obtained from this study are the amount of sensitivity of the effective parameters on the response of the tank in such a way that response of the structure is more sensitive to the changes of the density and the soil modulus of elasticity and changes of the friction coefficient between the surfaces and foundation and internal angle friction do not have tangible effect on the response.

\section{Data Availability}

Requests for access to these data should be made to the corresponding author e-mail address mazharfatahi@ gmail.com.

\section{Conflicts of Interest}

The authors declare that there are no conflicts of interest regarding the publication of this paper.

\section{References}

[1] R. M. Richard, C. J. Allen, and J. E. Partridge, "Proprietary slotted beam connection designs," Modern Steel Construction, pp. 28-33, 1997.

[2] S.-K. Lee, J.-H. Park, B.-W. Moon, K.-W. Lee, and J. Kim, "Design of a bracing-friction damper system for seismic retrofitting," Smart Structures and Systems, vol. 4, no. 5, pp. 685-696, 2008.

[3] M. Heshmati, S. M. S. Kolbadi, and S. M. S. Kolbadi, "Comparison between strain-based vs. stress-based criteria in seismic performance evaluation of high arch dams," American Journal of Civil Engineering, vol. 3, no. 2-1, pp. 1-8, 2015.
[4] D. Bernal, "Amplification factors for inelastic dynamicp- $\Delta$ effects in earthquake analysis," Earthquake Engineering \& Structural Dynamics, vol. 15, no. 5, pp. 635-651, 1987.

[5] S. Maleki and M. Tabbakhha, "Numerical study of slottedweb-reduced-flange moment connection," Journal of Constructional Steel Research, vol. 69, no. 1, 7 pages, 2012.

[6] M. R. Adlparvar, M. G. Vetr, and F. Ghaffari, "The importance of panel zone shear strength on seismic behavior of improved slotted-web beam connections," International Journal of Steel Structures, vol. 17, no. 1, pp. 307-318, 2017.

[7] R. K. Mohammadi, M. Mirjalaly, M. Mirtaheri, and M. Nazeryan, "Comparison between uniform deformation method and genetic algorithm for optimizing mechanical properties of dampers," Earthquakes and Structures, vol. 14, no. 1, pp. 001-010, 2018.

[8] L. F. Ibarra and H. Krawinkler, "global collapse of frame structures under seismic excitations," PEER Report No. 2005/ 06, Pacific Earthquake Engineering Research Center, University of California, Berkeley, CA, USA, 2005.

[9] J. Kim and T. Kim, "Assessment of progressive collapseresisting capacity of steel moment frames," Journal of Constructional Steel Research, vol. 65, no. 1, pp. 169-179, 2009.

[10] M. Liu, "Progressive collapse design of seismic steel frames using structural optimization," Journal of Constructional Steel Research, vol. 67, no. 3, pp. 322-332, 2011.

[11] R. Villaverde, "Methods to assess the seismic collapse capacity of building structures: state of the art," Journal of Structural Engineering, vol. 133, no. 1, pp. 57-66, 2007.

[12] E. B. Williamson, "Evaluation of damage and P - $\Delta$ effects for systems under earthquake excitation," Journal of Structural Engineering, vol. 129, no. 8, pp. 1036-1046, 2003.

[13] M. A. Hariri-Ardebili, S. M. Seyed-Kolbadi, and M. Noori, "Response surface method for material uncertainty quantification of infrastructures," Shock and Vibration, vol. 2018, Article ID 1784203, 14 pages, 2018.

[14] M. Barkhori, S. Maleki, M. Mirtaheri, M. Nazeryan, and S. M. S. Kolbadi, "Investigation of shear lag effect on tension members fillet-welded connections consisting of single and double channel sections," Structural Engineering and Mechanics, vol. 74, no. 3, pp. 445-455, 2020.

[15] D. Vamvatsikos and C. A. Cornell, "Incremental dynamic analysis," Earthquake Engineering \& Structural Dynamics, vol. 31, no. 3, pp. 491-514, 2002.

[16] S. M. S. Kolbadi, H. Davoodian, and S. M. S. Kolbadi, "Evaluation of nonlinear behaviour of reinforced concrete frames by explosive dynamic loading using finite element method," Civil Engineering Journal, vol. 3, no. 12, 20 pages, 2017.

[17] M. Lou, H. Wang, X. Chen, and Y. Zhai, "Structure-soilstructure interaction: literature review," Soil Dynamics and Earthquake Engineering, vol. 31, no. 12, pp. 1724-1731, 2011.

[18] M. Bybordiani and Y. Arici, "Structure-soil-structure interaction of adjacent buildings subjected to seismic loading," Earthquake Engineering \& Structural Dynamics, vol. 48, no. 7, pp. 731-748, 2019.

[19] E. Mock and L. Cheng, "Performance of retaining walls with and without sound wall under seismic loads," Earthquakes and Structures, vol. 7, no. 6, pp. 909-935, 2014.

[20] F. E. M. A. P695, Quantifi Cation of Building Seismic Performance Factors, Federal Emergency Management Agency, Washington, DC, USA, 2009.

[21] F. Zareian and H. Krawinkler, "Simplifi ed performance-based earthquake engineering," report No. TB 169 stanford (CA), Stanford University, Stanford, CA, USA, 2009. 
[22] F. Zareian, H. Krawinkler, L. Ibarra, and D. Lignos, "Basic concepts and performance measures in prediction of collapse of buildings under earthquake ground motions," The Structural Design of Tall and Special Buildings, vol. 19, pp. 167-181, 2010.

[23] B. Tang, X. Lu, L. Ye, and W. Shi, "Evaluation of collapse resistance of $\mathrm{RC}$ frame structures for Chinese schools in seismic design categories B and C," Earthquake Engineering and Engineering Vibration, vol. 10, no. 3, pp. 369-377, 2011.

[24] C. Adam, L. F. Ibarra, and H. Krawinkler, "Evaluation of P-delta effects in non-deteriorating MDOF structures from equivalent SDOF systems," in Proceedings of 13th World Conference on Earthquake Engineering, Vancouver, BC, Canada, p. 3407, August 2004.

[25] A. Kaveh and P. Zakian, "An efficient seismic analysis of regular skeletal structures via graph product rules and canonical forms," Earthquakes and Structures, vol. 10, no. 1, pp. 25-51, 2016.

[26] S. W. Han and A. K. Chopra, "Approximate incremental dynamic analysis using the modal pushover analysis procedure," Earthquake Engineering \& Structural Dynamics, vol. 35, no. 15, pp. 1853-1873, 2006.

[27] S. W. Han, K.-H. Moon, and A. K. Chopra, "Application of MPA to estimate probability of collapse of structures," Earthquake Engineering \& Structural Dynamics, vol. 39, no. 11, pp. 1259-1278, 2010.

[28] B. Shafei, F. Zareian, and D. G. Lignos, "A simplified method for collapse capacity assessment of moment-resisting frame and shear wall structural systems," Engineering Structures, vol. 33, no. 4, pp. 1107-1116, 2011.

[29] Fema, Seismic Performance Assessment of Buildings, Applied Technology Council as ATC, Redwood, CA, USA, 2012.

[30] M. G. Vetr, "Effect of vertical flange stiffener on the ductility of slotted web exclusive connection on (I)-shape profiles through experimental investigation," Journal of Engineering Research, vol. 3, no. 4, 2015.

[31] H. E. Estekanchi, V. Valamanesh, and A. Vafai, "Application of endurance time method in linear seismic analysis," Engineering Structures, vol. 29, no. 10, pp. 2551-2562, 2007.

[32] E. Miranda and S. D. Akkar, "Dynamic instability of simple structural systems," Journal of Structural Engineering, vol. 129, no. 12, pp. 1722-1726, 2003.

[33] H. Takizawa and P. C. Jennings, "Collapse of a model for ductile reinforced concrete frames under extreme earthquake motions," Earthquake Engineering \& Structural Dynamics, vol. 8, no. 2, pp. 117-144, 1980.

[34] H. T. Riahi and H. E. Estekanchi, "Seismic assessment of steel frames with the endurance time method," Journal of Constructional Steel Research, vol. 66, no. 6, pp. 780-792, 2010.

[35] V. Valamanesh and H. E. Estekanchi, "A study of endurance time method in the analysis of elastic moment frames under three-directional seismic loading," Asian Journal of Civil Engineering (Building And Housing), vol. 11, no. 5, pp. 543562, 2010a.

[36] M. Alembagheri and H. E. Estekanchi, "Seismic assessment of unanchored steel storage tanks by endurance time method," Earthquake Engineering and Engineering Vibration, vol. 10, no. 4, pp. 591-603, 2011.

[37] A. Mirzaee and H. E. Estekanchi, "Performance based seismic retrofitting of steel frames by endurance time method," Earthquake Spectra, vol. 31, no. 1, pp. 383-402, 2013.

[38] H. Estekanchi, A. Vafaie, and M. Sadeghazar, "Endurance time method for seismic analysis and design of structures," Journal of Constructional Steel Research, vol. 11, no. 4, pp. 361-370, 2007. 